\title{
Review-Two-Dimensional Layered Materials for Energy Storage Applications
}

\author{
Pushpendra Kumar, ${ }^{\mathrm{a}, *, \mathrm{z}}$ Hatem Abuhimd, ${ }^{\mathrm{b}}$ Wandi Wahyudi, ${ }^{\mathrm{a}, *}$ Mengliu Li, ${ }^{\text {a }}$ Jun Ming, ${ }^{\text {a }}$ \\ and Lain-Jong $\mathrm{Li}^{\mathrm{a}, * *}$
}

${ }^{a}$ Physical Sciences and Engineering Division, King Abdullah University of Science and Technology,

Thuwal, 23955-6900, Saudi Arabia

${ }^{b}$ National Nanotechnology Center, King Abdulaziz City for Science and Technology, Riyadh 11442, Saudi Arabia

Rechargeable batteries are most important energy storage devices in modern society with the rapid development and increasing demand for handy electronic devices and electric vehicles. The higher surface-to-volume ratio two-dimensional (2D) materials, especially transition metal dichalcogenides (TMDCs) and transition metal carbide/nitrite generally referred as MXene, have attracted intensive research activities due to their fascinating physical/chemical properties with extensive applications. One of the growing applications is to use these 2D materials as potential electrodes for rechargeable batteries and electrochemical capacitors. This review is an attempt to summarize the research and development of TMDCs, MXenes and their hybrid structures in energy storage systems. (c) The Author(s) 2016. Published by ECS. This is an open access article distributed under the terms of the Creative Commons Attribution Non-Commercial No Derivatives 4.0 License (CC BY-NC-ND, http://creativecommons.org/licenses/by-nc-nd/4.0/), which permits non-commercial reuse, distribution, and reproduction in any medium, provided the original work is not changed in any way and is properly cited. For permission for commercial reuse, please email: oa@electrochem.org. [DOI: 10.1149/2.0051611jss] All rights reserved.

Manuscript received June 23, 2016. Published July 1, 2016. This paper is part of the JSS Focus Issue on Properties, Devices, and Applications Based on 2D Layered Materials.

The strong demand for futuristic energy-storage materials and devices are exceptionally increasing owing to the request of more powerful energy storage systems with excellent power density and better cycle lifetime. ${ }^{1,2}$ For this reason, serious efforts have been undertaken to improve the electrode performance to achieve significantly improved the capacity, high rate capability and longer cycle life. ${ }^{3}$ Recently, 2D materials (TMDCs and MXene) have attracted intensive research activities due to their potential for broad applications. ${ }^{4-6}$ TMDCs represent a family of layered materials $\mathrm{MX}_{2}$ (where $\mathrm{M}=$ one layer of transition metal and $X=$ chalcogens) as shown in Figure 1a. ${ }^{7-9}$ Figure $1 \mathrm{~b}$ represents, three main structural polytypes, $1 \mathrm{~T}, 2 \mathrm{H}$ and $3 \mathrm{R}$ of TMDCs. All three polytypes have layered structures with six fold trigonal prismatic coordination of transition metal atoms by the chalcogens within the TMDC layers. The term $1 \mathrm{~T}, 2 \mathrm{H}$ and $3 \mathrm{R}$ represents the presence of one (1), two (2) and three (3) layers in the tetragonal (T), hexagonal $(\mathrm{H})$ and rhombohedral $(\mathrm{R})$ unit cell respectively. Interestingly, TMDCs own varied electronic structure, thus possess insulating $\left(\mathrm{HfS}_{2}\right)$, semi-conducting $\left(\mathrm{MoS}_{2}, \mathrm{WS}_{2}\right)$, semi-metallic $\left(\mathrm{VS}_{2}, \mathrm{TiS}_{2}\right)$, and superconducting $\left(\mathrm{TaSe}_{2}, \mathrm{NbSe}_{2}\right)$ behaviors which make them more attractive. Figure 1c, represents the exfoliation process of bulk TMDCs by lithium, sodium or potassium ion intercalation into the interlayer space and form ion-intercalated compounds, which can be further sonicated in water or organic solvents to produce single/few layer TMDC dispersions. More excitingly, the layers of TMDCs are connected with weak van der Waals interactions which enable them to serve for wide range of energy applications including energy generator, ${ }^{10}$ energy storage ${ }^{11-14}$ and catalysis. ${ }^{15-19}$ On the other hand, MXenes ${ }^{20}$ are produced from the MAX phase which is defined with the composition $\mathrm{M}_{n+1} \mathrm{AX}_{n}$, where $\mathrm{M}=$ transition metal (i.e. $\mathrm{Ti}, \mathrm{V}, \mathrm{Cr}, \mathrm{Nb}$ ), $\mathrm{A}=$ group $\mathrm{A}$ element (i.e. $\mathrm{Al}, \mathrm{In}, \mathrm{Sn}, \mathrm{Si}), \mathrm{X}=$ carbon/nitrogen, and $n=1-3$. Careful inscription of the group-A element from the MAX phase resulting in the production of MXene ${ }^{20-24}$ as shown in Figures $1 \mathrm{~d}-1 \mathrm{e}$. One of the most studied applications of these $2 \mathrm{D}$ materials is to use them as electrodes for electrochemical capacitors and rechargeable batteries..$^{20,25,26}$ As compared to their bulk counterpart, nanostructured TMDCs show striking ability to store $\mathrm{Li}^{+} / \mathrm{Na}^{+}$and exhibit a superior specific capacity with improved stability. However, they are not stable

\footnotetext{
*Electrochemical Society Student Member.

**Electrochemical Society Member.

${ }^{\mathrm{z}}$ E-mail: physicsbhu@gmail.com
}

during cycling and reveal high irreversibility at high rates. ${ }^{11,14,20,24,25,27}$ Some strategies to overcome these issues, including the use of hybrid structures with conducting additives e.g. graphene, graphene oxide, CNTs and conducting polymers are in progress. ${ }^{12-14,27-39}$ Graphene sheets can effectively restrict the restacking of TMDCs layers, provide better conductivity, enlarge effective surface area and improve the cycling stability. ${ }^{12,14,27,31,33}$ Besides TMDCs, MXenes have become novel materials in the family of 2D materials, and are highly promising for lithium/sodium battery anodes as well as for capacitors and pseudo-capacitor applications. ${ }^{20,22,23,25,26}$ Regardless of noteworthy development, more improvements are needed for practical applications. ${ }^{40}$ Focus of the present short review is to emphasize the ongoing studies on the development of 2D materials and their hybrid structures to illustrate their advantages as potential electrodes for futuristic energy storage devices.

\section{Energy Storage Applications of Transition-Metal Dichalcogenides (TMDCs)}

TMDCs for lithium ion batteries (LIBs).- - Li-ion batteries (LIBs) are promising energy storage systems, widely used for portable consumer electronics. Generally, lithium metal oxides (e.g. $\mathrm{LiCoO}_{2}$, $\mathrm{LiFePO}_{4}, \mathrm{LiNi}_{\mathrm{x}} \mathrm{Co}_{\mathrm{y}} \mathrm{Mn}_{1-\mathrm{x}-\mathrm{y}} \mathrm{O}_{2}$, and $\mathrm{LiNi}_{0.5} \mathrm{Mn}_{1.5} \mathrm{O}_{4}$ ) and $\mathrm{V}_{2} \mathrm{O}_{5}$ etc. are favorable cathodes for present LIB technology ${ }^{41-46}$ due to their high chemical potential (vs. $\mathrm{Li} / \mathrm{Li}^{+}$). On the other hand, graphite is a frequently used anode material for LIBs because of its favorable layered structure, natural abundance and low cost. ${ }^{47,48}$ Nevertheless, graphite is unable to fulfill the increasing demands for high-energy power sources owing to its low capacity $\left(372 \mathrm{mAh} \mathrm{g}^{-1}\right)$. Recently, several 2D TMDCs (including $\mathrm{MoS}_{2}, \mathrm{MoSe}_{2}, \mathrm{WS}_{2}, \mathrm{WSe}_{2}, \mathrm{VS}_{2}, \mathrm{VS}_{4}$ and $\mathrm{TiS}_{2}$ ) have been extensively explored as LIB anodes due to their favorable layered structure for ion/electron migration and chemical stability. ${ }^{11,25,27,29,30,34,36,49-54,47-51}$ For example, Figure 2a shows the high resolution transmission electron microscopy (HRTEM) images for the anodes composed of mesoporous $\mathrm{MoS}_{2}, \mathrm{MoSe}_{2}, \mathrm{WS}_{2}$ and $\mathrm{WSe}_{2}$ respectively. ${ }^{21}$ Their charge-discharge curves in Figure $2 \mathrm{~b}$, and the cycling performance, coulombic efficiency $(0.1 \mathrm{C})$ and rate capabilities and capacity retention (from 0.1 to $2 \mathrm{C}$ ) in Figure $2 \mathrm{c}$ have shown promises in a high capacity anodes $\left(>600 \mathrm{mAh} \mathrm{g}^{-1}\right) .{ }^{27}$ However, the deprived electrical conductivity, aggravated stability during cycling, pulverization of electrodes and restacking of subunits 
(a)

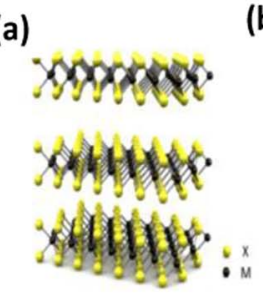

(b)

$\mathrm{MX}$

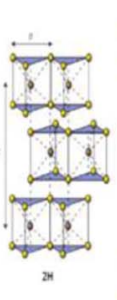

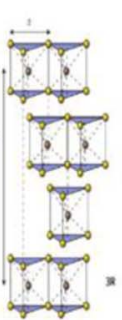

(d)

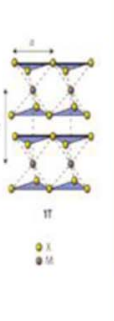

(c)

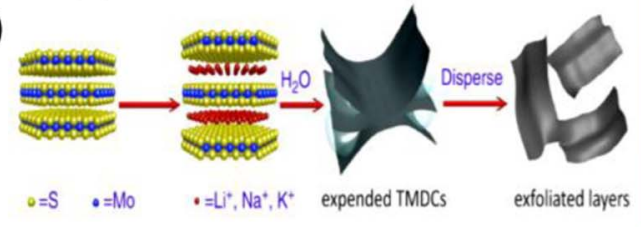

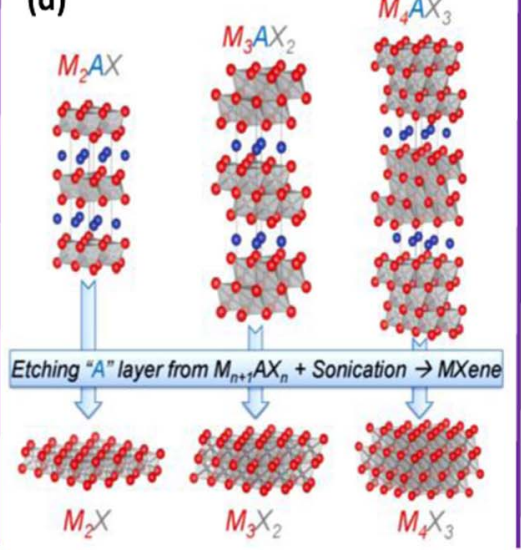

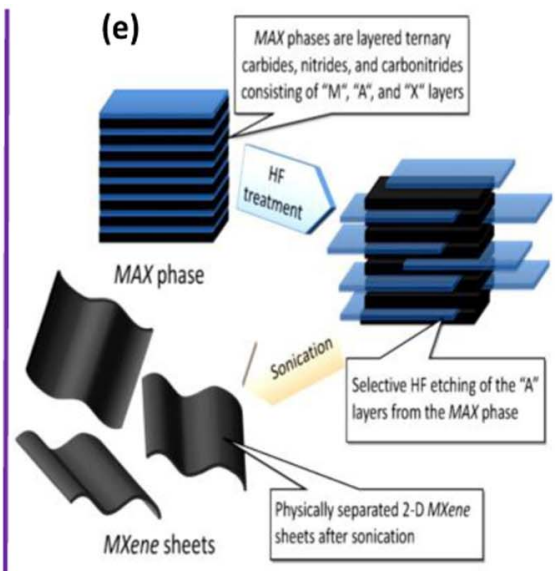

Figure 1. (a) Structure of TMDCs. ${ }^{7}$ Copyright 2011 Nature Publishing Group. (b)Three main structural polytypes identified as one tetragonal (1T), two hexagonal $(2 \mathrm{H})$, and three rhomohedral (3R). ${ }^{8}$ (c) Chemical exfoliation process of TMDCs. ${ }^{9}$ (d) Structure of MAX phases and the corresponding MXenes. ${ }^{23}$ (e) Schematic for the synthesis process of MXenes from MAX phases. ${ }^{21}$

for the pristine TMDC's are severe issues which deteriorate desirable electrochemical performances. To conquer these issues, the involved intercalation, conversion and oxidation reactions must be controlled. For examples, several conductive materials including conductive polymers and allotropes of carbon are proposed to construct hybrid electrodes. ${ }^{12-14,27-39,55}$ Layer-by-layer stacked hetero-structures of graphene-TMDCs is also suggested as an effective way to overcome above mentioned issues. . $^{14,31,33-35}$

TMDCs for sodium ion batteries (SIBs).-Codium ion batteries (SIBs) have emerged as an appealing alternative to LIBs because the resources of sodium metal are in principle unlimited in nature. Moreover, the ion transport mechanism of sodium resembles to lithium, thus the knowledge accrued for the development of LIBs could be directly applied to the SIBs. A variety of cathode materials have been reported for $\mathrm{SIB}^{56-58}$ application but identifying an appropriate negative electrode still remains as one of the prime challenges and hindrances toward the realization of $\mathrm{Na}$ ion full battery. Graphitic and non-graphitic carbons are not suitable anodes for SIBs as they are not capable to store sufficient sodium ions. The limited cycle life caused by the larger size of sodium ion and electrolyte decomposition is also a major issue ${ }^{59-62}$ Recently, TMDCs are being considered as an efficient and alternative anode for SIBs. ${ }^{35,63-65}$ Theoretical studies predicted that the binding between $\mathrm{Na}$ and $\mathrm{MoS}_{2}$ is thermodynamically advantageous; thus, $\mathrm{MoS}_{2}$ can be a favorable choice for sodium ions storage. ${ }^{35,58,64-66} \mathrm{~A}$ recent report by Wang et al. proved that the exfoliated $\mathrm{MoS}_{2}-\mathrm{C}$ composites exhibit a high capacity nearly $400 \mathrm{mAh}$ $\mathrm{g}^{-1}$ at $0.25 \mathrm{C}\left(100 \mathrm{~mA} \mathrm{~g}^{-1}\right)$ and a long cycle life. ${ }^{67}$ Remarkably high capability $\sim 290 \mathrm{mAh} \mathrm{g}^{-1}$ was also attained at high rate of $5 \mathrm{C} .{ }^{67}$ Very recently, Singh et al ${ }^{35}$ reported on the fabrication of a freestanding electrode synthesized by using acid treated $\mathrm{MoS}_{2} /$ Graphene composites for SIB anode applications as shown in Figure $2 \mathrm{~d} .{ }^{35}$ In the hybrid structure, graphene provides stability and superior conductivity networks allowing $\mathrm{Na}$ ions to undergo insertion reaction to the TMDCs.

TMDCs for supercapacitors.-Supercapacitors are promising energy storage systems for futuristic energy consumption devices with fast power delivery or uptake, exceptional power densities and better cyclability. ${ }^{68-70}$ Supercapacitors are categorized into two subgroups; (i) electric double layer capacitor (EDLC) and (ii) pseudo-capacitor, which works on the principle of rapid charge transfer through the redox reaction. The supercapacitors based on nanostructured TMDCs have been investigated extensively, as their inherent layered structures with sufficiently enough interlayer space with large surface areas can facilitate faster and easier ion diffusion/electron transport. For example, Figure 2e represents the low-magnification SEM image and Figure 2f shows the charge-discharge curves at different discharge currents for $\mathrm{WS}_{2} / \mathrm{RGO}$ hybrids in a supercapacitor assembly. ${ }^{32}$ Nanostructured $\mathrm{MoS}_{2}$ has been exotically used as capacitor electrode because it exhibits different oxidation states $\left(\mathrm{Mo}^{2+}\right.$ to $\left.\mathrm{Mo}^{6+}\right)$ which play roles in redox reaction. ${ }^{71,72}$ Another TMDC such as Titanium disulfide $\left(\mathrm{TiS}_{2}\right)$ also exhibits superior charge storage behaviors. ${ }^{73}$ Very recently, Chhowalla and co-workers have successfully reported that chemically exfoliated $\mathrm{MoS}_{2}$ nanosheets with the presence of 2D metallic $1 \mathrm{~T}$ phases, which is intrinsically hydrophilic and with high electrical conductivity, can be efficiently intercalated with different ions, such as $\mathrm{H}^{+}, \mathrm{Li}^{+}, \mathrm{Na}^{+}$and $\mathrm{K}^{+}$, resulting in ultrahigh capacitance ranging $\sim 400-700 \mathrm{Fcm}^{-3}{ }^{74}$

\section{Energy Storage Applications of MXenes}

MXenes for lithium ion batteries (LIBs).-The increasing demand of the high performance LIB anodes have led to extensive efforts toward discovery of new materials such as MXenes. ${ }^{20-24}$ Since their discovery, MXenesare being explored to used as LIB anodes owing to their promising features such as excellent electrical conductivity, exceptional mechanical properties, sufficiently large electrochemically active surfaces, and tunable bandgap energies. ${ }^{20-24}$ In addition, the structure of layered MXenes not only allows the intercalation of a variety of organic and inorganic molecules/ions but also can disperse easily in aqueous solutions (hydrophilic). MXenes promise improved electrochemical performance for LIBs since the intercalation of $\mathrm{Li}^{+}$ can be accomplished at low voltages $(-0.2 \mathrm{~V}$ to $0.6 \mathrm{~V})$ with low diffusion barriers. However, a trade-off between the low diffusion barriers and reversible capacity of LIBs with MXenes should be taken into account. Density functional theory (DFT) calculation predicts that the higher formula unit of MXenes leads to the fast diffusion rate but low reversible capacity than that of lower formula unit, and vice versa. ${ }^{20}$ For instance, $\mathrm{V}_{4} \mathrm{C}_{3} \mathrm{O}_{2}$ exhibits a low diffusion barrier $(0.42 \mathrm{eV})$ but its capacity is significantly dragged down $(148 \mathrm{mAh}$ $\left.\mathrm{g}^{-1}\right)$. By contrast, $\mathrm{V}_{2} \mathrm{CO}_{2}$ exhibits a higher diffusion barrier $(0.82 \mathrm{eV})$ but its capacity is much improved $\left(276 \mathrm{mAh} \mathrm{g}^{-1}\right) .^{75}$ Additionally, the lowest diffusion barrier $(0.07 \mathrm{eV})$ has been reported for $\mathrm{Ti}_{3} \mathrm{C}_{2}$, which is significantly lower than graphite $(0.3 \mathrm{eV}){ }^{23}$ Despite the aforementioned advantages of MXenes, their intercalated structures and involved mechanism need to be further explored. The study by M. Naguib et al. ${ }^{76}$ has been done to evidence the intercalation of $\mathrm{Li}^{+}$ within the layers of exfoliated $\mathrm{Ti}_{2} \mathrm{C}$ as the anode in LIBs. Recently, Zhang et al. reported on the synthesis of $\mathrm{Sn}^{4+}$ ion decorated highly conductive $\mathrm{Ti}_{3} \mathrm{C}_{2}$ MXene and its promising application for lithiumion anodes. ${ }^{77}$ Typical SEM and HRTEM images of the exfoliated $\mathrm{Ti}_{2} \mathrm{C}_{3}$ nanosheets produced by $\mathrm{HF}$ treatment of $\mathrm{Ti}_{2} \mathrm{AlC}$ are shown in Figures $3 \mathrm{a}-3 \mathrm{~d}$. The HRTEM images in Figures $3 \mathrm{c}-3 \mathrm{~d}$ confirms good crystallinity of the basal planes of the $\mathrm{Ti}_{3} \mathrm{C}_{2}$ phase after exfoliation. 

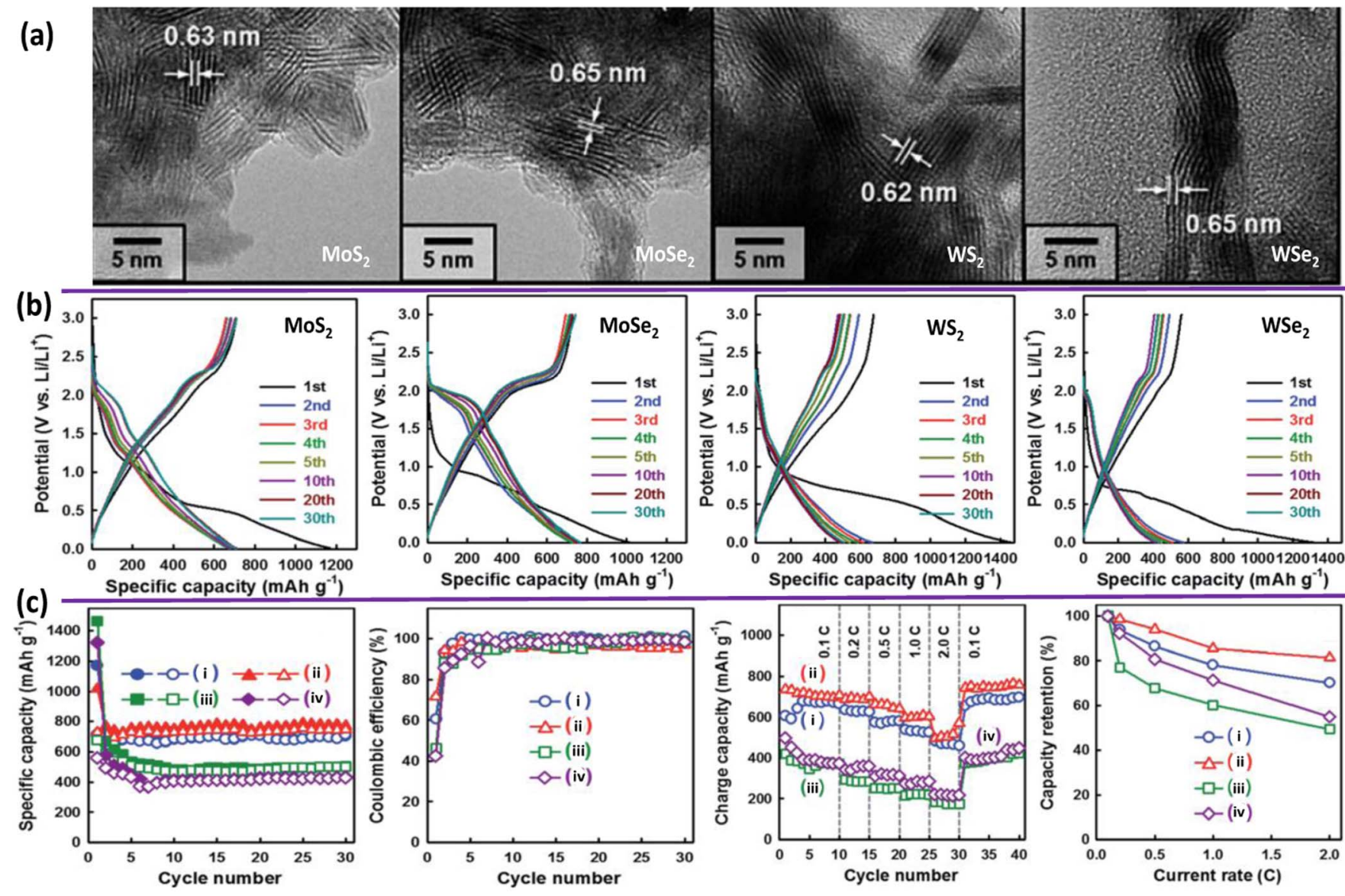

(d)

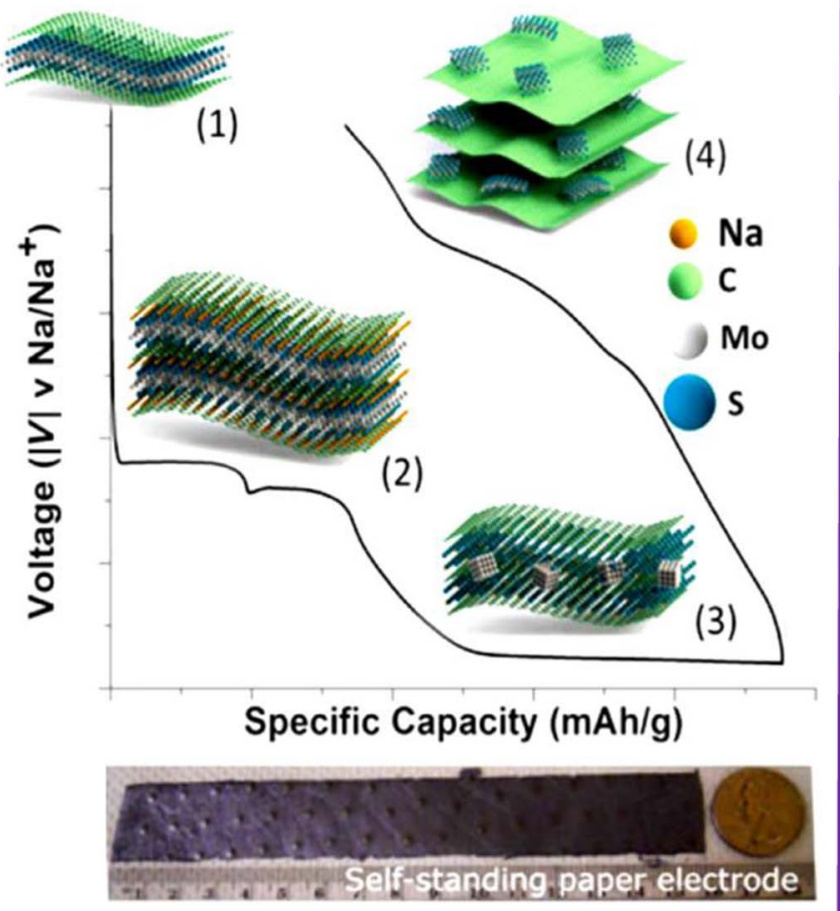

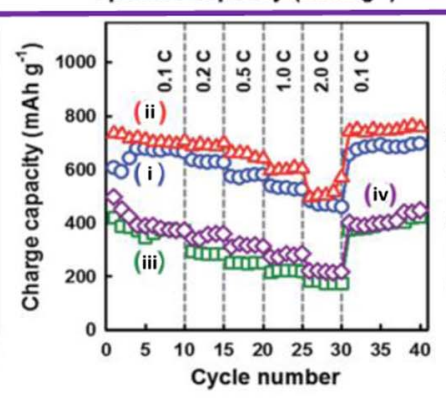
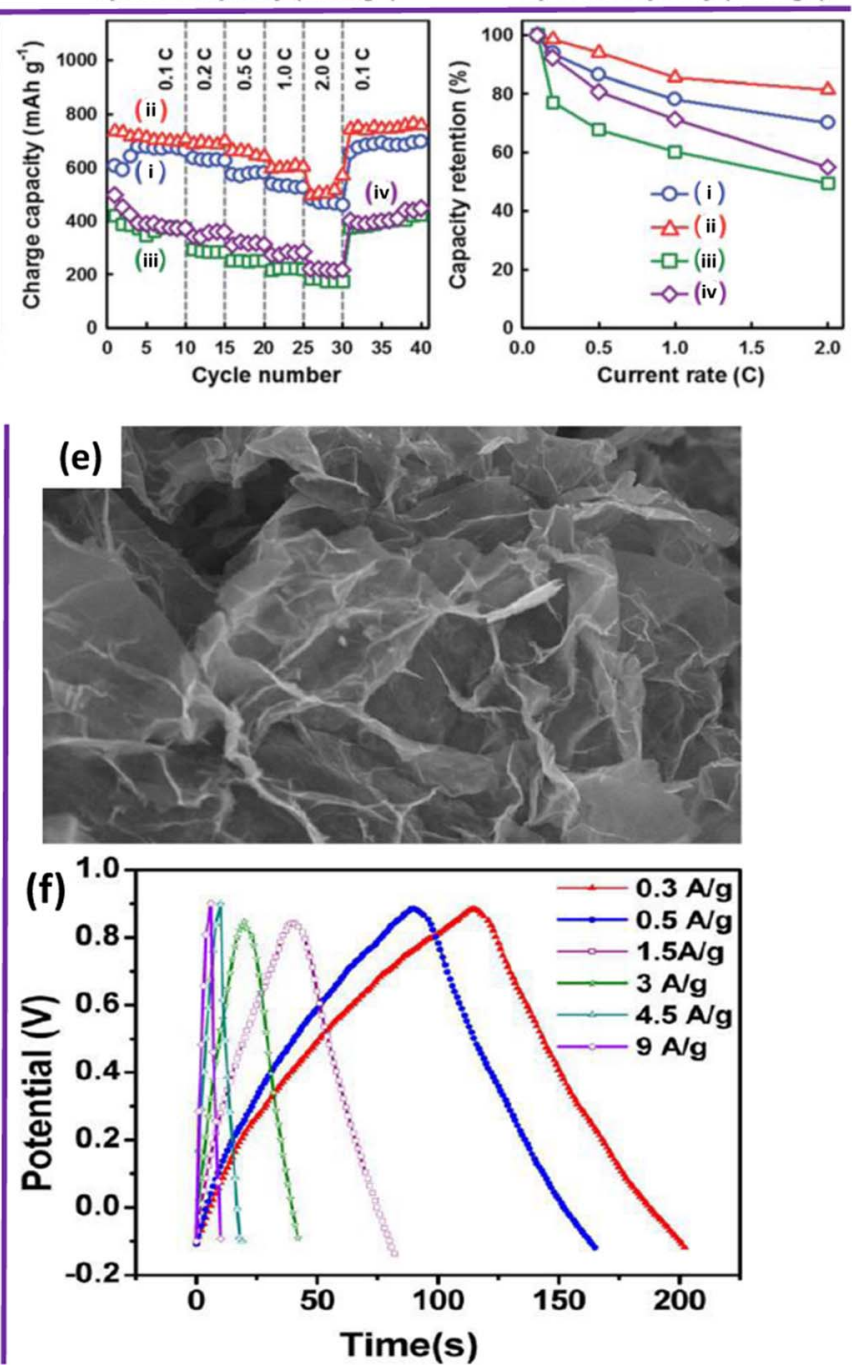

Figure 2. (a) HR-TEM images and (b) discharge-charge profiles of the mesoporous $\mathrm{MoS}_{2}, \mathrm{MoSe}_{2}$, $\mathrm{WS}_{2}$, and $\mathrm{WSe}_{2}$ respectively. (c) Cycling performance, coulombic efficiency at $0.1 \mathrm{C}$, rate capabilities and capacity retention from 0.1 to $2 \mathrm{C}$ of the mesoporous (i) $\mathrm{MoS}_{2}$, (ii) $\mathrm{MoSe}_{2}$, (iii) $\mathrm{WS}_{2}$, and (iv) $\mathrm{WSe}_{2}$ respectively. ${ }^{27}$ (d) Acid-exfoliated few-layer $\mathrm{MoS}_{2} / \mathrm{rGO}$ flakes for use as a self-standing flexible electrode in sodium-ion batteries. (1) rGO/MoS 2 composite electrodes are (2) first intercalated with Na. (3) At higher intercalation (sodiation), $\mathrm{MoS}_{2}$ nanosheets break down to $\mathrm{Mo}$ and $\mathrm{Na}_{2} \mathrm{~S}$. (4) During desodiation, MoS 2 nanosheets reassemble. ${ }^{35}$ (e) Low-magnification FESEM image (f) Charge-discharge curves at different discharge currents for WS $\mathrm{W}_{2} / \mathrm{RGO}$ hybrids. ${ }^{32}$ 

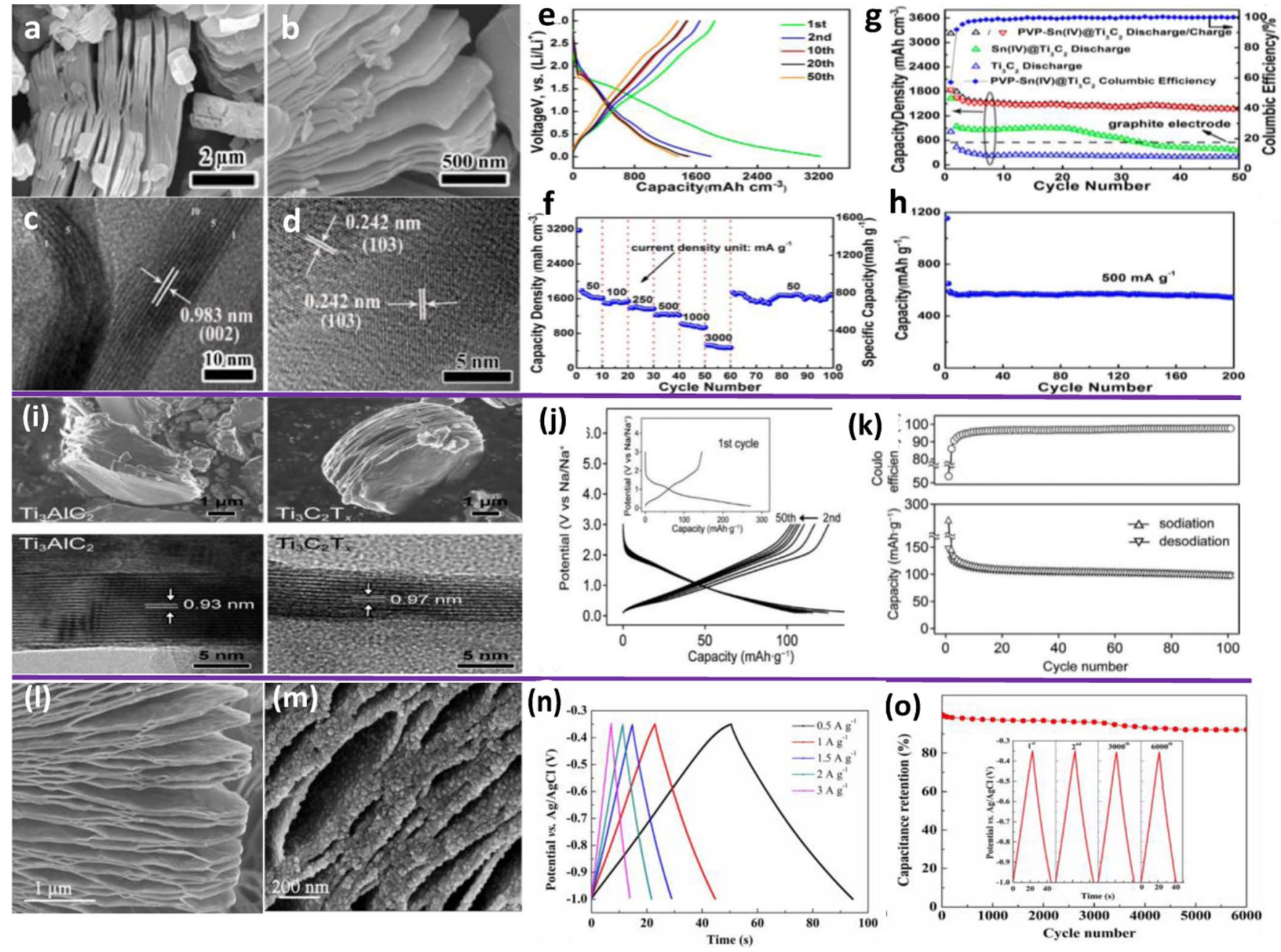

Figure 3. (a-d) Typical SEM and HRTEM images of the exfoliated $\mathrm{Ti}_{2} \mathrm{C}_{3}$ nanosheets produced by $\mathrm{HF}$ treatment of $\mathrm{Ti}_{2} \mathrm{AlC}$; (e) The galvanostatic charge/discharge curves at $216.5 \mathrm{mAh} / \mathrm{cm}^{-3}(\mathrm{C} / 10)$ rate. (f) Rate performance of nanocomposite electrodes (g) Cycling performance and Coulombic efficiency at a current density of $216.5 \mathrm{mAcm}^{-3}\left(0.1 \mathrm{Ag}^{-1}\right)$. (h) Cycling performance of PVP-Sn(IV)@ $\mathrm{Ti}_{3} \mathrm{C}_{2}$ at a current density of $500 \mathrm{mAg}^{-1} .77$ (i) SEM and TEM images for Ti $\mathrm{AlC}_{2}$ and $\mathrm{Ti}_{3} \mathrm{C}_{2} \mathrm{Tx}(\mathrm{j})$ Sodiation/desodiation potential profiles and $(\mathrm{k})$ cycle performance for $\mathrm{Ti}_{3} \mathrm{C}_{2} \mathrm{Tx}$ at $20 \mathrm{~mA} / \mathrm{g}$. The first sodiation-desodiation potential profiles are shown in the inset of (a) ${ }^{78} \mathrm{SEM}$ image of (l) typical as-fabricated $\mathrm{Ti}_{3} \mathrm{C}_{2} ;(\mathrm{m}) \mathrm{TiO}_{2}-\mathrm{Ti}_{3} \mathrm{C}_{2}$ nanocomposite (n) The typical galvanostatic charge-discharge (GCD) curves of the $\mathrm{TiO}_{2}-\mathrm{Ti}_{3} \mathrm{C}_{2}$ electrode for current densities of $0.5,1,1.5,2$ and $3 \mathrm{Ag}^{-1}$ and (o) the galvanostatic cycling curve of $\mathrm{TiO}_{2}-\mathrm{Ti}_{3} \mathrm{C}_{2}$ electrode $(6000 \mathrm{GCD}$ cycles), the inset of (o), the galvanostatic cycling data collected at $1 \mathrm{Ag}^{-1} .80$

Figures $3 \mathrm{e}-3 \mathrm{f}$ show the galvanostatic charge/discharge profiles of the PVP-Sn(IV)@ $\mathrm{Ti}_{3} \mathrm{C}_{2}$, which are measured between 0.01 and $3 \mathrm{~V}$ at a current density of $216.5 \mathrm{mAcm}^{-3}\left(0.1 \mathrm{~A} \mathrm{~g}^{-1}\right)$, and rate performance of nanocomposite electrodes. Figures $3 \mathrm{~g}-3 \mathrm{~h}$ cycling performance and coulombic efficiency at a current density of $216.5 \mathrm{~mA} \mathrm{~cm}^{-3}(0.1 \mathrm{~A}$ $\mathrm{g}^{-1}$ ) and cycling performance of PVP-Sn(IV)@ $\mathrm{Ti}_{3} \mathrm{C}_{2}$ at a current density of $500 \mathrm{~mA} \mathrm{~g}{ }^{-1} \cdot{ }^{77}$ To date, only few MXene materials have been studied for LIBs, such as: $\mathrm{Ti}_{2} \mathrm{CTx}, \mathrm{Nb}_{2} \mathrm{CT}_{\mathrm{x}}, \mathrm{Ti}_{3} \mathrm{C}_{2} \mathrm{~T}_{\mathrm{x}}$, and $\mathrm{V}_{2} \mathrm{CT}_{\mathrm{x}}$, where $T_{x}$ represents the functional surface termination groups. Considering that there are more than 70 reported members belonging to MAX phases, further improvement in electrochemical performance of LIBs with various MXenes are expected.

MXenes for sodium ion batteries (SIBs).-_The layered structure of MXenes which can facilitate the $\mathrm{Na}^{+}$storage, has been considered as promising anodes for SIBs due to their better stability at high C-rates. However, the sodiation-desodiation mechanism within the layers of MXenes is still not fully understood. Furthermore, only few MXene materials have been used for SIB anodes, such as $\mathrm{Ti}_{3} \mathrm{C}_{2} \mathrm{~T}_{\mathrm{x}}$ as shown in Figures $3 \mathrm{i}-3 \mathrm{k} .{ }^{78}$ This study further reports that a small fraction of $\mathrm{Na}^{+}$remains in the structure of MXenes event after full desodiation, resulting in the increase in interlayers distance from $9.7 \AA$ to $12.5 \AA^{78}{ }^{78}$ This is because the trapped $\mathrm{Na}^{+}$, in conjunction with penetrated solvent molecule lead to expansion of interlayer distance during the initial cycles of sodiation-desodiation by pillaring and swelling mechanisms. Further structural change in layered MXenes was not observed upon subsequent sodiation-desodiation cycles, resulting in good capacity retention. However, formation of SEI on the anode of SIBs still remains a predictable issue which needs to be investigated.

MXenes for supercapacitor.-MXenes have also been considered as promising electrodes for supercapacitors owing to their large volumetric capacitances at high current densities. Comparing to conventional intercalation compounds, MXenes offer better stability with a variety of cations. Intercalation mechanism within the layered MXene has not been fully understood. Recently, it is reported that small cations can intercalates spontaneously into the interlayer spaces of MXenes, whereas the intercalation of larger cations involves the swelling of interlayer. ${ }^{79}$ Among the members of MXenes family, $\mathrm{Ti}_{3} \mathrm{C}_{2} \mathrm{~T}_{\mathrm{x}}$ is widely studied for supercapacitor owing to its large volumetric capacitances at high current densities and spontaneous intercalation for a variety of cations. Recently, the surface modification of $\mathrm{Ti}_{3} \mathrm{C}_{2} \mathrm{~T}_{\mathrm{x}}$ to form $\mathrm{TiO}_{2} / \mathrm{Ti}_{3} \mathrm{C}_{2}$ hybrid structures has been reported as shown in Figures $31-30 .{ }^{80}$ In the report, $\mathrm{TiO}_{2}$ nanoparticles have been incorporated into the surface of $\mathrm{Ti}_{3} \mathrm{C}_{2}$ nanosheets and then used as an 
supercapacitor electrode, yielding significantly improved specific capacitance and cycling stability (92\% of its initial capacitance). ${ }^{80}$ The nanocrystalline $\mathrm{TiO}_{2}$ is believed to improve the accessibility of MXenes for intercalation of cations, resulting in a higher capacity than that of un-modified MXenes.

\section{Conclusions}

The emergent need for more powerful energy sources has attracted critical attention due to the exceptionally increasing demands. The use of 2D materials and their hybrid structures for energy storage devices (batteries and supercapacitors) offers excellent opportunities to overcome the challenges owned by growing energy needs. In the present review, we highlight the ongoing studies on the development of $2 \mathrm{D}$ materials as the potential electrodes for energy storage systems. Regardless of significant research development attained in the energy storage of the 2D materials, some issues associated with this field still persists. We hope that this contribution could promote further investigations on electrode developments using 2D materials for futuristic energy storage devices.

\section{References}

1. P. G. Bruce, S. A. Freunberger, L. J. Hardwick, and J. M. Tarascon, Nat Mater, 11 19 (2012).

2. P. Kumar, F. Y. Wu, L. H. Hu, S. A. Abbas, J. Ming, C. N. Lin, J. Fang, C. W. Chu and L. J. Li, Nanoscale, 7, 8093 (2015).

3. J. Ming, M. Li, P. Kumar, and L. J. Li, Acs Nano, 10, 6037 (2016).

4. H. N. Li, Y. M. Shi, M. H. Chiu, and L. J. Li, Nano Energy, 18, 293 (2015)

5. M. Chhowalla, H. S. Shin, G. Eda, L. J. Li, K. P. Loh, and H. Zhang, Nat Chem, 5, 263 (2013).

6. M. C. Lemme, L. J. Li, T. Palacios, and F. Schwierz, Mrs Bull, 39, 711 (2014).

7. B. Radisavljevic, A. Radenovic, J. Brivio, V. Giacometti, and A. Kis, Nat Nanotechnol, 6, 147 (2011).

8. Q. H. Wang, K. Kalantar-Zadeh, A. Kis, J. N. Coleman, and M. S. Strano, Nat Nan otechnol, 7, 699 (2012)

9. J. Zheng, H. Zhang, S. H. Dong, Y. P. Liu, C. T. Nai, H. S. Shin, H. Y. Jeong, B. Liu, and K. P. Loh, Nat Commun, 5, 2995 (2014).

10. W. Z. Wu, L. Wang, Y. L. Li, F. Zhang, L. Lin, S. M. Niu, D. Chenet, X. Zhang, Y. F. Hao, T. F. Heinz, J. Hone, and Z. L. Wang, Nature, 514, 470 (2014)

11. T. Stephenson, Z. Li, B. Olsen, and D. Mitlin, Energ Environ Sci, 7, 209 (2014).

12. G. Z. Sun, J. Q. Liu, X. Zhang, X. W. Wang, H. Li, Y. Yu, W. Huang, H. Zhang, and P. Chen, Angew Chem Int Edit, 53, 12576 (2014)

13. G. Z. Sun, X. Zhang, R. Z. Lin, J. Yang, H. Zhang, and P. Chen, Angew Chem Int Edit, 54, 4651 (2015).

14. X. H. Cao, Y. M. Shi, W. H. Shi, X. H. Rui, Q. Y. Yan, J. Kong, and H. Zhang, Small, 9, 3433 (2013)

15. Y. G. Li, H. L. Wang, L. M. Xie, Y. Y. Liang, G. S. Hong, and H. J. Dai, J Am Chem Soc, 133, 7296 (2011).

16. Y. H. Chang, C. T. Lin, T. Y. Chen, C. L. Hsu, Y. H. Lee, W. J. Zhang, K. H. Wei, and L. J. Li, Adv Mater, 25, 756 (2013).

17. Z. Y. Yin, B. Chen, M. Bosman, X. H. Cao, J. Z. Chen, B. Zheng, and H. Zhang, Small, 10, 3537 (2014).

18. C. B. Ma, X. Y. Qi, B. Chen, S. Y. Bao, Z. Y. Yin, X. J. Wu, Z. M. Luo, J. Wei, H. L. Zhang, and H. Zhang, Nanoscale, 6, 5624 (2014).

19. J. Z. Chen, X. J. Wu, L. S. Yin, B. Li, X. Hong, Z. X. Fan, B. Chen, C. Xue, and H. Zhang, Angew Chem Int Edit, 54, 1210 (2015).

20. C. Eames and M. S. Islam, J Am Chem Soc, 136, 16270 (2014).

21. M. Naguib, O. Mashtalir, J. Carle, V. Presser, J. Lu, L. Hultman, Y. Gogotsi, and M. W. Barsoum, Acs Nano, 6, 1322 (2012).

22. M. Naguib, M. Kurtoglu, V. Presser, J. Lu, J. J. Niu, M. Heon, L. Hultman, Y. Gogotsi, and M. W. Barsoum, Adv Mater, 23, 4248 (2011).

23. M. Naguib, V. N. Mochalin, M. W. Barsoum, and Y. Gogotsi, Adv Mater, 26, 992 (2014).

24. O. Mashtalir, M. Naguib, V. N. Mochalin, Y. Dall'Agnese, M. Heon, M. W. Barsoum, and Y. Gogotsi, Nat Commun, 4, 1716 (2013).

25. Y. Xie, M. Naguib, V. N. Mochalin, M. W. Barsoum, Y. Gogotsi, X. Q. Yu, K. W. Nam, X. Q. Yang, A. I. Kolesnikov, and P. R. C. Kent, J Am Chem Soc, 136, 6385 (2014)

26. E. Yang, H. Ji, J. Kim, H. Kim, and Y. Jung, Phys Chem Chem Phys, 17, 5000 (2015).

27. Y. Y. Lee, G. O. Park, Y. S. Choi, J. K. Shon, J. Yoon, K. H. Kim, W. S. Yoon, H. Kim, and J. M. Kim, Rsc Adv, 6, 14253 (2016).

28. E. G. D. Firmiano, A. C. Rabelo, C. J. Dalmaschio, A. N. Pinheiro, E. C. Pereira, W. H. Schreiner, and E. R. Leite, Adv Energy Mater, 4, 1301380 (2014)

29. Y. Y. Zhao, L. Kuai, Y. G. Liu, P. P. Wang, H. Arandiyan, S. F. Cao, J. Zhang, F. Y. Li, Q. Wang, B. Y. Geng, and H. Y. Sun, Sci Rep, 5, 8722 (2015).
30. Q. H. Weng, X. Wang, X. B. Wang, C. Zhang, X. F. Jiang, Y. Bando, and D. Golberg, J Mater Chem A, 3, 3097 (2015).

31. Z. Wang, T. Chen, W. X. Chen, K. Chang, L. Ma, G. C. Huang, D. Y. Chen, and J. Y. Lee, J Mater Chem A, 1, 2202 (2013).

32. S. Ratha and C. S. Rout, Acs Appl Mater Inter, 5, 11427 (2013).

33. K. Chang and W. X. Chen, Acs Nano, 5, 4720 (2011).

34. H. Hwang, H. Kim, and J. Cho, Nano Lett, 11, 4826 (2011).

35. L. David, R. Bhandavat, and G. Singh, Acs Nano, 8, 1759 (2014)

36. V. H. Pham, K. H. Kim, D. W. Jung, K. Singh, E. S. Oh, and J. S. Chung, J Power Sources, 244, 280 (2013)

37. Y. Shi, Y. Wang, J. I. Wong, A. Y. Tan, C. L. Hsu, L. J. Li, Y. C. Lu, and H. Y. Yang, Sci Rep, 3, 2169 (2013).

38. Y. Jing, E. O. Ortiz-Quiles, C. R. Cabrera, Z. F. Chen, and Z. Zhou, Electrochim Acta, 147, 392 (2014)

39. D. H. Youn, C. Jo, J. Y. Kim, J. Lee, and J. S. Lee, J Power Sources, 295, 228 (2015).

40. H. Ming, P. Kumar, W. J. Yang, Y. Fu, J. Ming, W. J. Kwak, L. J. Li, Y. K. Sun, and J. W. Zheng, Acs Sustain Chem Eng, 3, 3086 (2015).

41. M. S. Whittingham, Chem Rev, 104, 4271 (2004)

42. B. Kang and G. Ceder, Nature, 458, 190 (2009).

43. Y. Wang and G. Z. Cao, Adv Mater, 20, 2251 (2008).

44. S. Q. Wang, S. R. Li, Y. Sun, X. Y. Feng, and C. H. Chen, Energ Environ Sci, 4, 2854 (2011).

45. P. Kumar and L. H. Hu, J Alloy Compd, 655, 79 (2016).

46. P. Kumar, F. Y. Wu, T. Chou, and L. H. Hu, J Alloy Compd, 632, 126 (2015).

47. M. Endo, C. Kim, K. Nishimura, T. Fujino, and K. Miyashita, Carbon, 38, 183 (2000).

48. S. Komaba, T. Itabashi, B. Kaplan, H. Groult, and N. Kumagai, Electrochem Commun, 5, 962 (2003).

49. R. J. Chen, T. Zhao, W. P. Wu, F. Wu, L. Li, J. Qian, R. Xu, H. M. Wu, H. M. Albishri, A. S. Al-Bogami, D. Abd El-Hady, J. Lu, and K. Amine, Nano Lett, 14, 5899 (2014)

50. G. L. Holleck and J. R. Driscoll, Electrochim Acta, 22, 647 (1977).

51. X. Huang, Z. Y. Zeng, and H. Zhang, Chem Soc Rev, 42, 1934 (2013).

52. R. Bhandavat, L. David, and G. Singh, J Phys Chem Lett, 3, 1523 (2012).

53. C. Q. Feng, L. F. Huang, Z. P. Guo, and H. K. Liu, Electrochem Commun, 9, 119 (2007).

54. K. Shiva, H. S. S. R. Matte, H. B. Rajendra, A. J. Bhattacharyya, and C. N. R. Rao, Nano Energy, 2, 787 (2013).

55. X. L. Zhao, Y. J. Mai, H. Luo, D. P. Tang, B. Lee, C. U. Huang, and L. Z. Zhang, Appl Surf Sci, 288, 736 (2014).

56. S. W. Kim, D. H. Seo, X. H. Ma, G. Ceder, and K. Kang, Adv Energy Mater, 2, 710 (2012).

57. S. Y. Lim, H. Kim, J. Chung, J. H. Lee, B. G. Kim, J. J. Choi, K. Y. Chung, W. Cho, S. J. Kim, W. A. Goddard, Y. Jung, and J. W. Choi, P Natl Acad Sci USA, 111, 599 (2014).

58. C. S. Park, H. Kim, R. A. Shakoor, E. Yang, S. Y. Lim, R. Kahraman, Y. Jung, and J. W. Choi, J Am Chem Soc, 135, 2787 (2013).

59. R. Alcantara, P. Lavela, G. F. Ortiz, and J. L. Tirado, Electrochem Solid St, 8, A222 (2005).

60. Y. L. Cao, L. F. Xiao, M. L. Sushko, W. Wang, B. Schwenzer, J. Xiao, Z. M. Nie, L. V. Saraf, Z. G. Yang, and J. Liu, Nano Lett, 12, 3783 (2012).

61. K. Tang, L. J. Fu, R. J. White, L. H. Yu, M. M. Titirici, M. Antonietti, and J. Maier, Adv Energy Mater, 2, 873 (2012).

62. S. Wenzel, T. Hara, J. Janek, and P. Adelhelm, Energ Environ Sci, 4, 3342 (2011).

63. C. L. Wang, Y. Xu, Y. G. Fang, M. Zhou, L. Y. Liang, S. Singh, H. P. Zhao, A. Schober, and Y. Lei, J Am Chem Soc, 137, 3124 (2015).

64. G. S. Bang, K. W. Nam, J. Y. Kim, J. Shin, J. W. Choi, and S. Y. Choi, Acs Appl Mater Inter, 6, 7084 (2014).

65. X. F. Wang, X. Shen, Z. X. Wang, R. C. Yu, and L. Q. Chen, Acs Nano, 8, 11394 (2014).

66. M. Mortazavi, C. Wang, J. K. Deng, V. B. Shenoy, and N. V. Medhekar, J Power Sources, 268, 279 (2014)

67. Y. X. Wang, K. H. Seng, S. L. Chou, J. Z. Wang, Z. P. Guo, D. Wexler, H. K. Liu, and S. X. Dou, Chem Commun, 50, 10730 (2014).

68. C. Y. Chu, J. T. Tsai, and C. L. Sun, Int J Hydrogen Energ, 37, 13880 (2012).

69. J. Liu, Y. H. Xue, M. Zhang, and L. M. Dai, Mrs Bull, 37, 1265 (2012).

70. Y. Huang, J. J. Liang, and Y. S. Chen, Small, 8, 1805 (2012).

71. L. J. Cao, S. B. Yang, W. Gao, Z. Liu, Y. J. Gong, L. L. Ma, G. Shi, S. D. Lei, Y. H. Zhang, S. T. Zhang, R. Vajtai, and P. M. Ajayan, Small, 9, 2905 (2013).

72. A. Ramadoss, T. Kim, G. S. Kim, and S. J. Kim, New J Chem, 38, 2379 (2014).

73. M. A. Bissett, S. D. Worrall, I. A. Kinloch, and R. A. W. Dryfe, Electrochim Acta, 201, 30 (2016).

74. M. Acerce, D. Voiry, and M. Chhowalla, Nat Nanotechnol, 10, 313 (2015).

75. M. Ashton, R. G. Hennig, and S. B. Sinnott, Applied Physics Letters, 108, 023901 (2016).

76. M. Naguib, J. Come, B. Dyatkin, V. Presser, P.-L. Taberna, P. Simon, M. W. Barsoum, and Y. Gogotsi, Electrochemistry Communications, 16, 61 (2012).

77. J. M. Luo, X. Y. Tao, J. Zhang, Y. Xia, H. Huang, L. Y. Zhang, Y. P. Gan, C. Liang, and W. K. Zhang, Acs Nano, 10, 2491 (2016).

78. S. Kajiyama, L. Szabova, K. Sodeyama, H. Iinuma, R. Morita, K. Gotoh, Y. Tateyama, M. Okubo, and A. Yamada, ACS Nano, 10, 3334 (2016).

79. M. D. Levi, M. R. Lukatskaya, S. Sigalov, M. Beidaghi, N. Shpigel, L. Daikhin, D. Aurbach, M. W. Barsoum, and Y. Gogotsi, Advanced Energy Materials, 5, 1400815 (2015).

80. J. Zhu, Y. Tang, C. Yang, F. Wang, and M. Cao, Journal of The Electrochemical Society, 163, A785 (2016). 